\title{
Recommendations for clear aligner therapy using digital or plaster study casts
}

\author{
Hsiu-Ching Ko ${ }^{1 *}$, Weitao Liu', Derek Hou', Sepideh Torkan', Charles Spiekerman² and Greg J. Huang ${ }^{1}$
}

\begin{abstract}
Background: Clear aligner therapy has evolved considerably since its introduction 20 years ago. Clinicians have become more experienced with aligner therapy, but little is known about the types of malocclusions that clinicians currently treat with aligners. Similarly, it is not known if viewing digital vs plaster models has any impact on the treatment planning process for aligners. The aim of this study was to assess which types of malocclusions are recommended for treatment with clear aligners, and also to determine if recommendations for aligner treatment differed when using digital versus plaster models.

Methods: Sixteen orthodontists treatment planned 20 cases at two time points with either the same or different model formats (digital versus plaster). As part of the treatment planning process, they were asked whether each patient was a good candidate for Invisalign ${ }^{\circledR}$ treatment, and if not, why. Generalized estimating equations regression (GEE), the permutation test, and a logistic regression model with GEE were used to analyze the data.

Results: No significant difference was found between the Invisalign ${ }^{\circledR}$ choices in the digital model group and those in the plaster model group at T1 $(p=0.59)$. There was no significant difference between the agreement rate of the different formats group and that of the same format group $(p=0.97)$. Cases with extractions had less Invisalign ${ }^{\oplus}$ recommendations (15\%) compared to cases with no extractions $(55 \%)(p=0.0015)$. Cases with surgery had less Invisalign ${ }^{\circledast}$ recommendations (29\%) compared to cases with no surgery (57\%) $(p=0.035)$.
\end{abstract}

Conclusions: In this study, viewing orthodontic records with digital versus plaster models did not influence decisions about Invisalign ${ }^{\circledR}$ recommendations. Additionally, the orthodontists in this study tended to not recommend Invisalign ${ }^{\circledast}$ for extraction cases, surgical cases, or difficult cases.

\section{Background}

Orthodontic patients increasingly expect more esthetic and comfortable treatment options. Clear aligners meet these criteria, but many orthodontists do not feel that they can be utilized for all patients $[1,2]$. Studies have shown that aligners are able to perform some types of orthodontic tooth movement successfully, while more complex movements, like extrusions, anteroposterior correction, and severe rotations, pose more challenges [3-5]. During the past few years, Align Technology has attempted to address these concerns by introducing improvements to the Invisalign ${ }^{\circ}$ product that allow for better control tooth movement. The effect of these improvements on

\footnotetext{
* Correspondence: grafenauerko@gmail.com; hck1015@uw.edu 'Department of Orthodontics, School of Dentistry, University of Washington, 1959 NE Pacific ST, Health Sciences Center, D-569, Box 357446, Seattle, WA 98195-7446, USA

Full list of author information is available at the end of the article
}

clinician's attitudes towards cases that can be successfully treated with aligners has not yet been investigated.

Along with the increasing prevalence of aligner therapy, digital models are gradually replacing plaster models and will eventually become the new standard for orthodontic records. However, many orthodontists still find familiarity in plaster models that can be physically articulated and measured, and studies have reported that models are the single most important orthodontic record for treatment planning $[6,7]$. Several studies have looked at the accuracy of digital models, and in general, they have been found to be reasonably accurate compared to plaster models [8-12]. However, more importantly, it is not known whether assessing a case with digital instead of plaster models may influence the final treatment plan.

The purpose of this study was to assess which types of malocclusions were or were not recommended for treatment with clear aligners and also to determine if these 
decisions differed when using digital versus plaster models.

\section{Methods}

This study was approved by the Human Subjects Division at the University of Washington. We recruited 16 orthodontists, all of whom were in practice for a minimum of 5 years and did not routinely use digital models (other than for Invisalign ${ }^{\circ}$ cases) (Table 1). The orthodontists were shown how to navigate the OrthoCad software (Align Technology, San Jose, CA) prior to viewing the records in the study. The orthodontists assessed a total of 20 cases at the beginning of the study (T1) and reassessed these same 20 cases again after at least 3 months had passed (T2).

Orthodontists were divided into two groups based upon matching for gender and years in practice (as well as possible). The demographics of the two groups are shown in Table 1. One group was shown the same format models at the two time points, and the second group was shown different format models at the two time points. The pre-determined assignment scheme (shown in Fig. 1) ensured that all combinations of treatment planning with either digital or plaster models were equally distributed over the two time points. This information was used to determine if the type of model used affected the decision regarding the use of Invisalign ${ }^{\circ}$.

Ten different case types were planned to be included in the study to represent the breadth of cases typically seen in practice, such as Class I with various degrees of crowding, Class II division 1, Class II division 2, Class III, and open bite. We purposely weighted the sample towards cases with at least moderate difficulty, as they would offer better ability to discriminate between aligner recommendations. A list of all patients started in 2012 at the UW Graduate Orthodontic Clinic patient population was reviewed to identify cases that matched the categories planned to be included in the study. Ultimately two sets of ten cases each were selected based on matching

Table 1 The demographic characteristics of the orthodontists

\begin{tabular}{lll}
\hline $\begin{array}{l}\text { Group } \\
\text { of practitioners }\end{array}$ & 1 & 2 \\
& Same format of models & Different formats of models \\
\hline Gender & & \\
Male & 6 & 4 \\
Female & 2 & 4 \\
Years in practice & & \\
Average & 22.8 & 27.6 \\
$<10$ & 2 & 1 \\
$11 \sim 20$ & 1 & 1 \\
$21 \sim 30$ & 2 & 3 \\
$>30$ & 3 & 3 \\
\hline
\end{tabular}

of age, gender, A-P, vertical, transverse, and amount of crowding. A summary of these cases is presented in Table 2.

The records of these 20 cases were assembled and imported into Dolphin Imaging (Patterson Dental, Chatsworth, CA) to be accessed during the study, and included intra- and extra-oral photographs, as well as the panoramic and lateral cephalometric radiographs. The plaster models were scanned using the iTero HD 2.9 intra-oral scanner (Align Technology, San Jose, CA), and the digital casts were shown using OrthoCad software (Align Technology, San Jose, CA). All patient identifiers were removed, and only study numbers were used during the evaluation by orthodontists. Subject's eyes were blocked out in all facial photographs. A standardized form was used for treatment planning each patient (Fig. 2).

At the initial treatment planning session, orthodontists were shown the intra- and extra-oral photos, panoramic radiographs, lateral cephalometric radiographs, and the study models in either digital or plaster format. After at least 3 months had passed the orthodontists were asked to treatment plan the same cases again, using either digital or plaster models based on the pre-assigned scheme (Fig. 1).

\section{Statistical analysis}

A generalized estimating equations regression was utilized to determine if there was a difference in the recommendation for Invisalign ${ }^{\circ}$ treatment based upon the type of model (plaster versus digital) that was viewed. The permutation test was utilized to assess if there was a difference between the agreement rate of those who viewed the models twice with different formats and that of those who viewed the models twice with the same format. The level of significance was set at $p<0.05$. Additionally, a logistic regression model with GEE was utilized to help explain why Invisalign $^{\circ}$ was not recommended as a treatment option.

\section{Results}

There was no significant difference between the percentage recommending Invisalign ${ }^{\bullet}$ in the digital model group and that in the plaster model group at T1 $(p=0.59)$. In the digital model group, $75.6 \%$ of initial treatment plans at T1 did not recommend using Invisalign ${ }^{\circ}$, while this rate was $76.9 \%$ in the plaster group (Table 3 ).

Additionally, there was no significant difference between the agreement rate of those who viewed models twice with different formats and that of those who viewed models twice with the same format $(p=0.97)$. Thus, the percentages of cases that practitioners felt could be treated by Invisalign ${ }^{\circ}$ did not appear to be influenced by the manner (plaster versus digital) in which the models were presented (Table 4). Therefore, we 


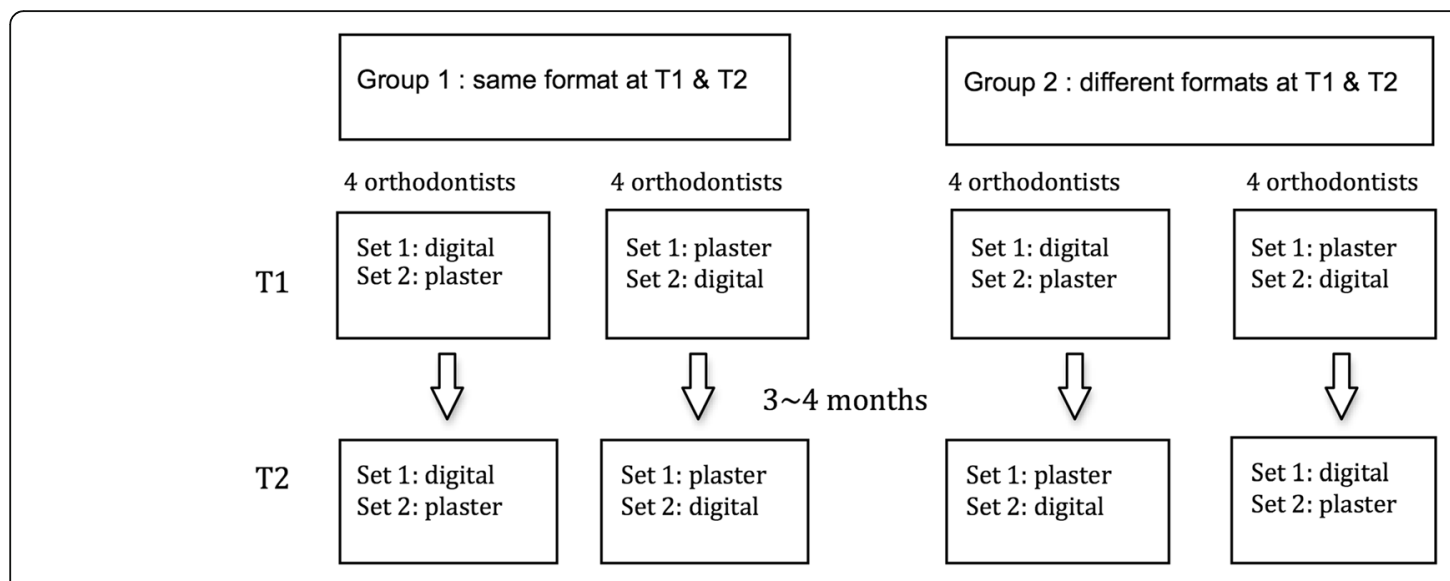

Fig. 1 Scheme for assignment of orthodontists and cases

decided to pool the recommendations from all 16 assessors at the first assessment time point in order to assess reasons for not recommending aligners.

Table 5 reports the case characteristics, number and percentage of surgical plans, extraction plans, and Invisalign $^{\bullet}$ recommendations. The main reasons are also listed for each case. (The maximum number of recommendations for each parameter is 16.)

In the Class I category, it was evident that cases requiring extractions were not judged to be good candidates for Invisalign'. Two Class I open bite cases (recommended extractions by $56 \%$ and $91 \%$ of the judges, respectively) also were not judged to be good candidates for Invisalign ${ }^{\circ}$. Only one of the subjects in the Class I category was judged to be a reasonable candidate for Invisalign ${ }^{\circ}$ (case 1-2), and the percentage of the raters who recommended extraction for this patient was the lowest in this category (19\%).

In the Class II division 1 category, extractions were included in the treatment plans of the majority for patients other than patient 6-2. This subject had minimal crowding and only a half-cusp A-P discrepancy. Almost half of the practitioners felt this case could be treated with Invisalign ${ }^{\circ}$.

The two patients in the adolescent Class II division 2 category did not have high extraction rates. However, only one (case $7-1$ ) had more than $50 \%$ of the orthodontists recommend Invisalign ${ }^{\circ}$ as an option. This patient had moderate crowding in the upper arch and less growth potential, while case 7-2 had minimal crowding and more growth potential. Functional appliances were suggested for both of these patients, but more for case 7-2. The patient with more need for functional appliances seemed to have a lower rate of recommendations for Invisalign ${ }^{\circ}$. In the adult Class II division 2 category, the patient with less need for extractions had a higher rate of recommendations for Invisalign ${ }^{\circ}$.

Finally, in the Class III patients, it was shown that the patients with less severe A-P discrepancies had higher rates of recommendations for Invisalign ${ }^{\circ}$. The cases requiring surgery were not judged to be good candidates for Invisalign ${ }^{\circ}$.

Table 2 Summary of patient characteristics

\begin{tabular}{|c|c|c|c|c|c|c|c|c|}
\hline & \multirow[t]{2}{*}{ Pair } & \multicolumn{3}{|l|}{ Set 1} & \multicolumn{3}{|l|}{ Set 2} & \multirow{2}{*}{$\begin{array}{l}\text { Main condition } \\
\text { of interest }\end{array}$} \\
\hline & & Case no. & Age & Gender & Case no. & Age & Gender & \\
\hline \multirow[t]{4}{*}{ Class I } & 1 & $1-1$ & 15 years and 1 month & $\mathrm{F}$ & $1-2$ & 16 years and 6 months & $\mathrm{F}$ & Crowding \\
\hline & 2 & $2-1$ & 14 years and 5 months & M & $2-2$ & 14 years and 9 months & M & Crowding \\
\hline & 3 & $3-1$ & 21 years and 9 months & M & $3-2^{*}$ & 22 years and 11 months & M & Adult; posterior crossbite \\
\hline & 4 & $4-41$ & 13 years and 7 months & M & $4-2$ & 14 years and 2 months & M & Anterior open bite \\
\hline \multirow[t]{2}{*}{ Class II div 1} & 5 & $5-1$ & 13 years and 4 months & $\mathrm{F}$ & $5-2$ & 13 years and 5 months & $\mathrm{F}$ & Crowding \\
\hline & 6 & $6-1$ & 13 years and 9 months & $\mathrm{F}$ & $6-2$ & 12 years and 8 months & $\mathrm{F}$ & Deepbite \\
\hline \multirow[t]{2}{*}{ Class II div 2} & 7 & $7-1$ & 14 years and 1 month & $\mathrm{F}$ & $7-2$ & 12 years and 7 months & $\mathrm{F}$ & Adolescent; deepbite \\
\hline & 8 & $8-1$ & 30 years and 9 months & $\mathrm{F}$ & $8-2$ & 28 years and 9 months & $\mathrm{F}$ & Adult \\
\hline \multirow[t]{2}{*}{ Class III } & 9 & $9-1$ & 15 years and 5 months & $\mathrm{F}$ & $9-2$ & 15 years and 1 month & $\mathrm{F}$ & Mild A-P discrepancy \\
\hline & 10 & $10-1$ & 16 years and 6 months & $\mathrm{F}$ & $10-2$ & 16 years and 7 months & $\mathrm{F}$ & Severe A-P discrepancy \\
\hline
\end{tabular}

*This patient had a Class II posterior malocclusion 


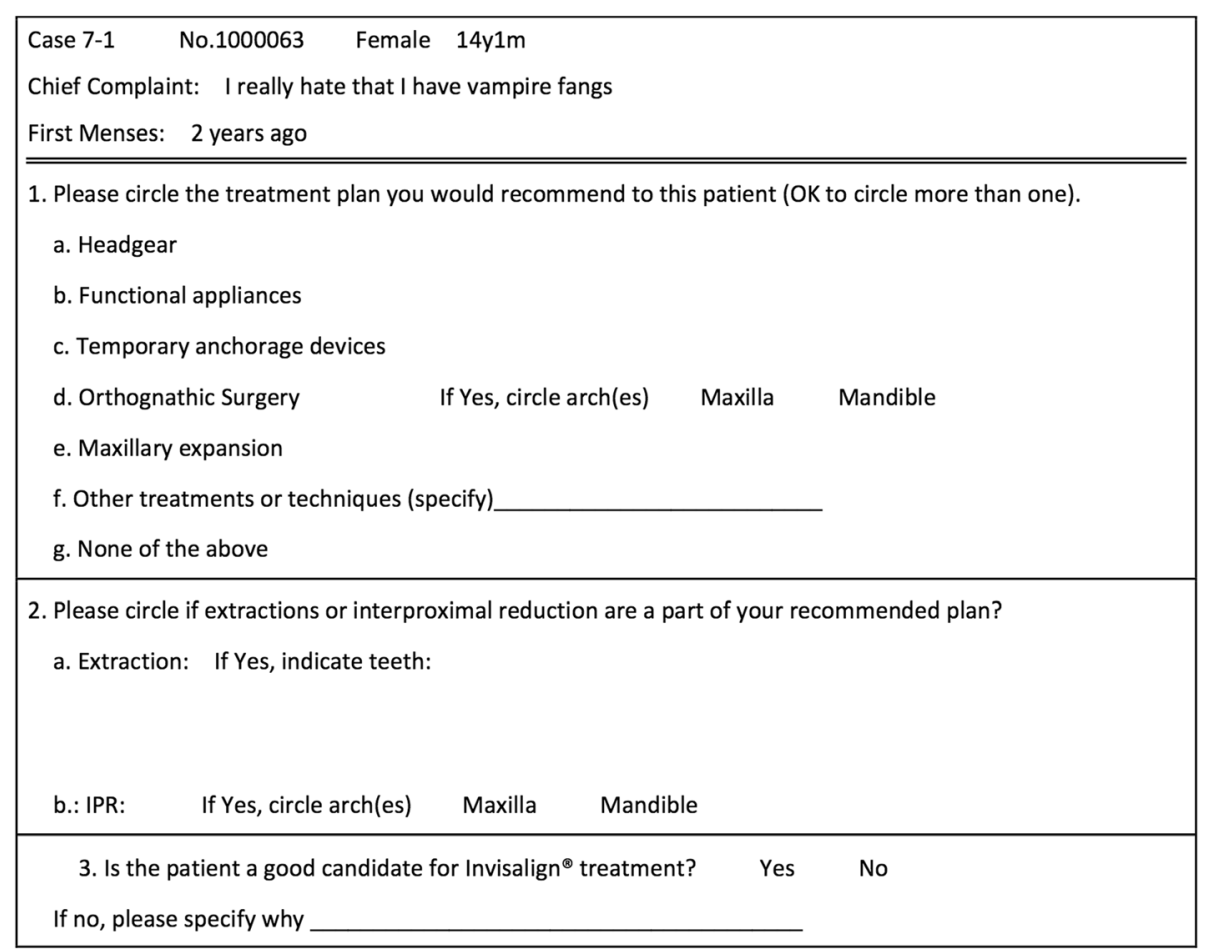

Fig. 2 Example data collection form

The results shown in Table 6 outline the reasons given for not recommending Invisalign ${ }^{\circ}$ in the total treatment plans. The highest one was extraction plan (36\%), and the second one was surgery (23\%). Others were concerned about the severity of case, anchorage, and A-P correction.

Among those cases which were fairly equal in the recommendation for or against using aligners (cases 1-2, 6-2, $7-1,8-1,8-2,9-2)$, there was a significant difference among extractions and surgery choices (Table 7). Cases with extractions had significantly fewer Invisalign ${ }^{\circ}$ recommendations (15\%) compared to cases with no extractions $(55 \%)(p=0.0015)$. Additionally, cases with surgery had significantly fewer Invisalign ${ }^{\circ}$ recommendations (29\%) compared to cases with no surgery $(57 \%)(p=0.035)$.

\section{Discussion}

This study was performed to assess what types of malocclusions orthodontists felt would be suitable for treatment with aligners, and also to determine if using digital versus plaster models would affect treatment plans. It has been reported that digital models are an adequate replacement for plaster models with respect to treatment planning for fixed appliance therapy [13, 14], but no one has assessed this for aligner therapy. In the present study, we did not find a difference in decisions regarding the use of aligners with plaster versus digital models. Good intra-rater agreement was observed when aligners were chosen as a treatment option with all combinations of digital or plaster models.

Table 5 shows that the most common reasons for not recommending Invisalign ${ }^{\circ}$ were extractions (36\%), orthognathic surgery (23\%), difficult tooth movements (12\%), concerns about anchorage (10\%), and A-P correction (10\%). This supports the finding of Phan and Ling's publication in 2007 that stated the following conditions were contra-indicated for aligners: crowding and spacing over $5 \mathrm{~mm}$, skeletal anterior-posterior discrepancies of more than $2 \mathrm{~mm}$, centric-relation and centric-occlusion discrepancies, open bites, severely rotated teeth, extrusion of teeth, severely tipped teeth, teeth with short clinical crowns, and arches with multiple missing teeth [1]. Table 7 also reveals that cases with extractions or

Table 3 Percentage of decisions aligners not recommended at T1

\begin{tabular}{|c|c|c|c|c|c|c|}
\hline \multirow[t]{2}{*}{ Invisalign ${ }^{\oplus}$ recommendation } & \multicolumn{2}{|l|}{ Models } & \multirow[t]{2}{*}{ Difference } & \multirow{2}{*}{\multicolumn{2}{|c|}{$\begin{array}{l}95 \% \text { confidence } \\
\text { interval of difference }\end{array}$}} & \multirow[t]{2}{*}{$p$ value } \\
\hline & Digital & Plaster & & & & \\
\hline$\%$ of decisions not recommending & $75.60 \%$ & $76.90 \%$ & $1.25 \%$ & $-3.30 \%$ & $5.80 \%$ & 0.59 \\
\hline
\end{tabular}


Table 4 Intra-rater agreement when viewing the case twice

\begin{tabular}{|c|c|c|c|c|c|}
\hline \multirow[t]{2}{*}{ Invisalign ${ }^{\circledast}$ recommendation } & \multicolumn{2}{|l|}{ Models } & \multirow{2}{*}{$\begin{array}{l}\text { Difference in } \\
\text { agreement }\end{array}$} & \multirow{2}{*}{$\begin{array}{l}\text { 95\% confidence } \\
\text { interval of difference }\end{array}$} & \multirow[t]{2}{*}{$p$ value } \\
\hline & Different formats & Same format & & & \\
\hline Same decision at T1 and T2 & $82 \%$ & $81 \%$ & $1 \%$ & $-21 \%$ & 0.97 \\
\hline
\end{tabular}

surgery had fewer Invisalign ${ }^{\bullet}$ recommendations compared to cases with no extractions or surgery.

When treating crowded cases with extractions, it is critical to be aware of canine position, mesio-distal root tipping adjacent to the extraction sites during space closure, incisor torque, and rotation of teeth. In the present study, it was shown that cases requiring extractions were not judged to be good candidates for Invisalign'. In 2003, Bollen, et al. reported that only $29 \%$ of those with two or more premolars extracted were able to complete space closure with the initial series of aligners, and none completed the overall treatment [15].

Table 5 Characteristics, treatment plans, and Invisalign ${ }^{\circledast}$ recommendations

\begin{tabular}{|c|c|c|c|c|c|c|}
\hline Category & Case no. & Main characteristics & $\begin{array}{l}\text { Times surgery } \\
\text { recommended (\%) }\end{array}$ & $\begin{array}{l}\text { Times extraction } \\
\text { recommended (\%) }\end{array}$ & $\begin{array}{l}\text { Times aligners not } \\
\text { recommended (\%) }\end{array}$ & $\begin{array}{l}\text { Main reasons for not } \\
\text { recommending aligners } \\
\text { (times mentioned) }\end{array}$ \\
\hline \multirow[t]{8}{*}{ Class I } & $1-1$ & Moderate crowding, protrusive profile & 0 & 15 (94\%) & $14(88 \%)$ & Extraction case (10) \\
\hline & $1-2$ & $\begin{array}{l}\text { Moderate crowding, } \\
\text { Mx right lateral crossbite } \\
\text { Straight profile }\end{array}$ & 0 & $3(19 \%)$ & $6(38 \%)$ & $\begin{array}{l}\text { Extraction case (2) } \\
\text { Crossbite (2) }\end{array}$ \\
\hline & $2-1$ & $\begin{array}{l}\text { Moderate to severe crowding; } \\
\text { High canine }\end{array}$ & 0 & $12(75 \%)$ & $13(81 \%)$ & $\begin{array}{l}\text { Extraction case (7) } \\
\text { Rotation (3) }\end{array}$ \\
\hline & $2-2$ & $\begin{array}{l}\text { Moderate to severe crowding, } \\
\text { Mx laterals in crossbite }\end{array}$ & 0 & $14(88 \%)$ & $14(88 \%)$ & $\begin{array}{l}\text { Extraction case (9) } \\
\text { Difficult case (2) }\end{array}$ \\
\hline & $3-1$ & $\begin{array}{l}\text { Adult } \\
\text { Severe crowding } \\
\text { Bilateral posterior crossbite }\end{array}$ & $2(12 \%)$ & $12(75 \%)$ & $15(94 \%)$ & $\begin{array}{l}\text { Extraction case (6) } \\
\text { Difficult case (3) } \\
\text { Surgery case (2) } \\
\text { Crossbite (2) }\end{array}$ \\
\hline & $3-2^{*}$ & $\begin{array}{l}\text { Adult } \\
\text { Unilateral posterior crossbite, severely } \\
\text { proclined upper incisors, class II }\end{array}$ & $8(50 \%)$ & $13(81 \%)$ & $15(94 \%)$ & $\begin{array}{l}\text { Extraction case (6) } \\
\text { Surgery case (5) } \\
\text { Difficult case (2) }\end{array}$ \\
\hline & $4-1$ & Anterior open bite, facial asymmetry & $7(44 \%)$ & $9(56 \%)$ & $14(88 \%)$ & $\begin{array}{l}\text { Surgery case (6) } \\
\text { Extraction case (3) } \\
\text { Anchorage (2) } \\
\text { Open bite (2) }\end{array}$ \\
\hline & $4-2$ & $\begin{array}{l}\text { Anterior open bite } \\
\text { Mild crowding, protrusive lips }\end{array}$ & $1(6 \%)$ & $15(94 \%)$ & $14(88 \%)$ & $\begin{array}{l}\text { Extraction case (7) } \\
\text { Surgery case (2) } \\
\text { Difficult case (2) } \\
\text { Open bite (2) }\end{array}$ \\
\hline \multirow[t]{4}{*}{ Class II Div 1} & $5-1$ & Moderate crowding & 0 & $13(81 \%)$ & $14(88 \%)$ & Extraction case (11) \\
\hline & $5-2$ & Moderate crowding & $1(6 \%)$ & 15 (94\%) & $14(88 \%)$ & $\begin{array}{l}\text { Extraction case (6) } \\
\text { Difficult case (2) } \\
\text { Surgery case (2) } \\
\text { Anchorage (2) }\end{array}$ \\
\hline & $6-1$ & $\begin{array}{l}\text { Deepbite } \\
\text { Full-cusp class II } \\
\text { Retrognathic mandible }\end{array}$ & $8(50 \%)$ & $11(69 \%)$ & $13(81 \%)$ & $\begin{array}{l}\text { Surgery case (5) } \\
\text { Extraction case (4) } \\
\text { Difficult case (2) } \\
\text { Anchorage (2) }\end{array}$ \\
\hline & $6-2$ & $\begin{array}{l}\text { Deepbite } \\
\text { Half-cusp class II; }\end{array}$ & $1(6 \%)$ & $2(12 \%)$ & $9(56 \%)$ & $\begin{array}{l}\text { Deepbite and deep } \\
\text { COS (3) } \\
\text { Extraction case (2) } \\
\text { (9 suggested } \\
\text { functional appliances) }\end{array}$ \\
\hline \multirow[t]{2}{*}{ Class II Div 2} & $7-1$ & $\begin{array}{l}\text { Deepbite, maxillary } \\
\text { moderate crowding }\end{array}$ & $1(6 \%)$ & $4(25 \%)$ & 7 (44\%) & $\begin{array}{l}\text { Extraction case (2) } \\
\text { ( } 3 \text { suggested } \\
\text { functional appliances) }\end{array}$ \\
\hline & $7-2$ & Deepbite & $2(12 \%)$ & 0 & $12(75 \%)$ & $\begin{array}{l}\text { AP correction (5) } \\
\text { (10 suggested } \\
\text { functional appliances) }\end{array}$ \\
\hline
\end{tabular}


Table 5 Characteristics, treatment plans, and Invisalign ${ }^{\oplus}$ recommendations (Continued)

\begin{tabular}{|c|c|c|c|c|c|c|}
\hline Category & Case no. & Main characteristics & $\begin{array}{l}\text { Times surgery } \\
\text { recommended (\%) }\end{array}$ & $\begin{array}{l}\text { Times extraction } \\
\text { recommended (\%) }\end{array}$ & $\begin{array}{l}\text { Times aligners not } \\
\text { recommended (\%) }\end{array}$ & $\begin{array}{l}\text { Main reasons for not } \\
\text { recommending aligners } \\
\text { (times mentioned) }\end{array}$ \\
\hline & $8-1$ & $\begin{array}{l}\text { Adult } \\
\text { Deepbite }\end{array}$ & $8(50 \%)$ & $3(19 \%)$ & $9(56 \%)$ & $\begin{array}{l}\text { Surgery case (3) } \\
\text { Extraction case (3) }\end{array}$ \\
\hline & $8-2$ & $\begin{array}{l}\text { Adult } \\
\text { Severe crowding }\end{array}$ & $3(19 \%)$ & $13(81 \%)$ & $14(88 \%)$ & $\begin{array}{l}\text { Extraction case (7) } \\
\text { Surgery case (3) } \\
\text { Difficult case (2) } \\
\text { Anchorage (2) }\end{array}$ \\
\hline \multirow[t]{4}{*}{ Class III } & $9-1$ & $\begin{array}{l}\text { Mild A-P discrepancy } \\
\text { Asymmetry }\end{array}$ & $12(75 \%)$ & $1(6 \%)$ & $9(56 \%)$ & $\begin{array}{l}\text { Surgery case (6) } \\
\text { AP correction (2) }\end{array}$ \\
\hline & $9-2$ & $\begin{array}{l}\text { Mild A-P discrepancy } \\
\text { Asymmetry }\end{array}$ & $2(12 \%)$ & 0 & $8(50 \%)$ & $\begin{array}{l}\text { Severity (3) } \\
\text { AP correction (3) }\end{array}$ \\
\hline & $10-1$ & $\begin{array}{l}\text { Anterior crossbite, } \\
\text { severe A-P discrepancy } \\
\text { Asymmetry }\end{array}$ & $10(63 \%)$ & $4(25 \%)$ & 15 (94\%) & $\begin{array}{l}\text { Surgery case (7) } \\
\text { Difficult case (4) } \\
\text { Anchorage (2) }\end{array}$ \\
\hline & $10-2$ & $\begin{array}{l}\text { Anterior crossbite, } \\
\text { severe A-P discrepancy } \\
\text { Asymmetry }\end{array}$ & $13(81 \%)$ & $3(19 \%)$ & $15(94 \%)$ & $\begin{array}{l}\text { Surgery case }(10) \\
\text { Deepbite or deep } \\
\operatorname{COS}(2)\end{array}$ \\
\hline
\end{tabular}

*This patient had a Class II posterior malocclusion

In a prospective study, Kravitz, et al. reported maxillary and mandibular canines achieved only about one third of the predicted rotation in a prospective study [2]. However, in 2015, Li, et al. reported that Invisalign ${ }^{\circledR}$ appliances were as successful as fixed appliances in correcting Class I adult extraction cases by assessing the overall improvement in the ABO-OGS scores in a multicenter randomized controlled trial. OGS scores were similar for alignment, occlusal relations, interproximal contacts, and root angulation, but Invisalign ${ }^{\bullet}$ OGS scores were not as good as braces in reference to occlusal contacts and buccolingual inclination [4].

When treating Class II and Class III cases, surgery or camouflage decisions (with or without extractions) were based on the severity of the A-P discrepancy. In this study, it was shown that practitioners were reluctant to treat cases requiring surgery with Invisalign ${ }^{\bullet}$. In surgical cases, fixed appliances are helpful for efficient dental

Table 6 The percentages of the reasons given for not recommending Invisalign ${ }^{\circledast}$

\begin{tabular}{ll}
\hline Reasons to not recommend Invisalign ${ }^{\oplus}$ & Percentage \\
\hline Deepbite, deep curve of Spee & 3 \\
A-P correction & 8 \\
Surgery case & 23 \\
Extraction case & 36 \\
7's not erupted & 1 \\
Rotation correction & 2 \\
Difficult case & 12 \\
Crossbite & 3 \\
Anchorage, control of movement & 10 \\
Open bite & 2 \\
Total & 100 \\
\hline
\end{tabular}

decompensation and inter-arch fixation during surgery. Although there are case reports of treatment with aligners for orthognathic surgery cases [16], many orthodontists feel that fixed appliances are more effective to control post-surgical tooth movement and inter-arch coordination.

Besides extraction and surgery, this study found that orthodontists were also concerned about anteroposterior correction. It has been reported that molar distalization in mild Class II malocclusions can be achieved with clear aligners $[3,5,17]$. Some authors have reported low success rates with Invisalign ${ }^{\bullet}$ for correcting large A-P discrepancies. In the official clinical guide of Invisalign ${ }^{\circ}$ treatment [18], it is recommended that for Class II cases, the amount of A-P correction be limited to $2-4 \mathrm{~mm}$. This correction is largely from dental, not skeletal, changes. For severe Class II malocclusions $(4 \mathrm{~mm}+)$, Invisalign ${ }^{\ominus}$ recommends using sagittal correctors prior to starting aligner therapy. In the official clinical guide of Invisalign $^{\bullet}$ treatment for Class III cases [19], the amount of Class III correction that can be achieved with aligners is under $2 \mathrm{~mm}$. This amount of anteroposterior correction can be achieved in several ways, including precision

Table 7 Extraction, surgery, and Invisalign ${ }^{\oplus}$ choices

\begin{tabular}{lllll}
\hline & \multicolumn{2}{l}{$\operatorname{lnvisalign}^{\oplus}$} & & $p$ value* $^{*}$ \\
\cline { 2 - 4 } & No Inv & Inv & \% Inv & \\
\hline Extractions & 37 & 46 & 55 & 0.0015 \\
No & 11 & 2 & 15 & \\
Yes & 11 & & & \\
Surgery & 31 & 41 & 57 & 0.035 \\
No & 17 & 7 & 29 & \\
Yes & 17 & & \\
\hline
\end{tabular}

*Logistic regression model with GEE 
cuts for elastics, sequential staging of tooth movements, optimized attachments, and incorporation of TADs. Likewise, large tooth movements may be challenging, as each aligner typically has less than $0.25 \mathrm{~mm}$ of programmed tooth movement $[2,3,5]$. Teeth that need significant rotation or translation will require many aligners to accomplish these movements. Vertical and transverse problems may also be difficult to correct, as indicated by the low number of recommendations for aligners when patients displayed these characteristics.

According to a clinical study in 2009, the mean accuracy of tooth movement with Invisalign ${ }^{\circ}$ was $41 \%$ [2]. During the past few years, Align Technology has launched new materials, techniques, and software to expand the scope of tooth movement, the management of extractions, the ability to correct anteroposterior relationships, and the correction of vertical problems [20-22]. In 2011, Align Technology claimed that Invisalign ${ }^{\circ}$ G4 attachments and SmartForce features provided greater root tip control for canines and central incisors, mesio-distal root uprighting, space closure, and improved optimized extrusion attachments for anterior open bites [20]. In 2013, Invisalign ${ }^{\circ}$ G5 featured more predictable deepbite correction by using new SmartForce attachments, precision bite ramps, pressure areas for the incisors and canines, and optimized premolar attachments for retention and extrusion to level the curve of Spee [21]. In 2014, Invisalign ${ }^{\circ} \mathrm{G} 6$ was engineered to improve clinical outcomes for orthodontic treatment of severe crowding and bimaxillary protrusion which require premolar extraction and maximum anchorage [22]. The new SmartStage technology, SmartForce, optimized retraction attachments, and optimized anchorage attachments are designed to eliminate unwanted tipping and anterior extrusion during retraction, to improve bodily movement during canine retraction, and to maximize posterior anchorage [22].

In this study, approximately $70 \%$ of the orthodontists had been in practice for more than 20 years, and half of the orthodontists were routinely treating patients with aligners. Only 3 cases out of 20 cases (15\%) had more than half of the practitioners recommend clear aligners. These cases tended to be the less severe malocclusions. While this percentage may seem low, including more challenging malocclusions allowed us to better investigate the reasons that aligners were not recommended.

Previous publications on the Invisalign ${ }^{\circ}$ technique have mainly covered technical aspects or materials or have presented results from case reports or case series. Orthodontists often recommend aligner therapy to patients based on their past experiences. In this study, most orthodontists avoided recommending aligners to patients requiring extractions, surgery, or difficult tooth movements. While Align Technology continues to release new materials, software, and features to broaden the scope of Invisalign ${ }^{\bullet}$ care, orthodontists may still be basing their recommendations from their experience with earlier Invisalign $^{\bullet}$ materials and techniques. Thus, Invisalign ${ }^{\bullet}$ may need to provide orthodontists with additional education and evidence in order to change their opinions regarding case selection.

\section{Conclusions}

In this study, viewing orthodontic records with digital versus plaster models did not influence decisions about Invisalign ${ }^{\circ}$ recommendations. Additionally, our sample of orthodontists tended to not recommend Invisalign ${ }^{\circ}$ to treat extraction cases, surgical cases, or difficult cases.

\section{Abbreviations}

GEE: Generalized estimating equations regression

\section{Funding}

We would like to thank Invisalign ${ }^{\circledR}$ for providing an intra-oral scanner for creating the digital scans, and Align Technology for providing $\$ 5000$ to assist with the cost of performing the study.

Availability of data and materials

Please contact the author for data requests.

\section{Authors' contributions}

HCK contributed to the data analysis and interpretation, drafting of the article, and critical revision of the article. WL contributed to the conception and design of the work, data collection, and critical revision of the article. DH and ST contributed to the data collection and critical revision of the article. CS contributed to the data analysis and interpretation and critical revision of the article. GJH contributed to the conception and design of the work, data analysis and interpretation, drafting of the article, and critical revision of the article. All authors gave the final approval of the version to be published.

\section{Ethics approval and consent to participate}

This project was approved by the Human Subjects Division at the University of Washington.

\section{Consent for publication}

Not applicable

\section{Competing interests}

The authors declare that they have no competing interests.

\section{Publisher's Note}

Springer Nature remains neutral with regard to jurisdictional claims in published maps and institutional affiliations.

\section{Author details}

${ }^{1}$ Department of Orthodontics, School of Dentistry, University of Washington, 1959 NE Pacific ST, Health Sciences Center, D-569, Box 357446, Seattle, WA 98195-7446, USA. ${ }^{2}$ Department of Biostatistics, School of Public Health, University of Washington, Seattle, USA.

Received: 15 May 2018 Accepted: 12 June 2018

Published online: 19 July 2018

\section{References}

1. Phan X, Ling PH. Clinical limitations of Invisalign. J Can Dent Assoc. 2007 Apr;73(3):263-6.

2. Kravitz ND, Kusnoto B, BeGole E, Obrez A, Agran B. How well does Invisalign work? A prospective clinical study evaluating the efficacy of tooth movement with Invisalign. Am J Orthod Dentofac Orthop. 2009:135:27-35

3. Rossini G, Parrini S, Castroflorio T, Deregibus A, Debernardi CL. Efficacy of clear aligners in controlling orthodontic tooth movement: a systematic review. Angle Orthod. 2015 Sep;85(5):881-9. 
4. Li W, Wang S, Zhang Y. The effectiveness of the Invisalign appliance in extraction cases using the the ABO model grading system: a multicenter randomized controlled trial. Int J Clin Exp Med. 2015;8(5):8276-82.

5. Simon M, Keilig L, Schwarze J, Jung BA, Bourauel C. Treatment outcome and efficacy of an aligner technique-regarding incisor torque, premolar derotation and molar distalization. BMC Oral Health. 2014;14:68. https://doi. org/10.1186/1472-6831-14-68.

6. Han UK, Vig KW, Weintraub JA, Vig PS, Kowalski CJ. Consistency of orthodontic treatment decisions relative to diagnostic records. Am J Orthod Dentofac Orthop. 1991;100(3):212-9.

7. Nijkamp PG, Habets $L L$, Aartman $I H$, Zentner A. The influence of cephalometrics on orthodontic treatment planning. Eur J Orthod. 2008; 30(6):630-5.

8. Hayashi K, Sachdeva AU, Saitoh S, Lee SP, Kubota T, Mizoguchi I. Assessment of the accuracy and reliability of new 3-dimensional scanning devices. Am J Orthod Dentofac Orthop. 2013;144(4):619-25.

9. Sousa MV, Vasconcelos EC, Janson G, Garib D, Pinzan A. Accuracy and reproducibility of 3-dimensional digital model measurements. Am J Orthod Dentofac Orthop. 2012;142(2):269-73.

10. Costalos PA, Sarraf K, Cangialosi TJ, Efstratiadis S. Evaluation of the accuracy of digital model analysis for the American Board of Orthodontics objective grading system for dental casts. Am J Orthod Dentofac Orthop. 2005;128(5):624-9.

11. Leifert MF, Leifert MM, Efstratiadis SS, Cangialosi TJ. Comparison of space analysis evaluations with digital models and plaster dental casts. Am J Orthod Dentofac Orthop. 2009;136(1):16.e1-4. discussion 16

12. Santoro M, Galkin S, Teredesai M, Nicolay OF, Cangialosi TJ. Comparison of measurements made on digital and plaster models. Am J Orthod Dentofac Orthop. 2003;124:101-5.

13. Rheude B, Sadowsky PL, Ferriera A, Jacobson A. An evaluation of the use of digital study models in orthodontic diagnosis and treatment planning. Angle Orthod. 2005;75(3):300-4

14. Whetten JL, Williamson PC, Heo G, Varnhagen C, Major PW. Variations in orthodontic treatment planning decisions of Class II patients between virtual 3-dimensional models and traditional plaster study models. Am J Orthod Dentofac Orthop. 2006;130(4):485-91.

15. Bollen AM, Huang G, King G, Hujoel P, Ma T. Activation time and material stiffness of sequential removable orthodontic appliance. Part 1: ability to complete treatment. Am J Orthod Dentofac Orthop. 2003;124(5):496-501.

16. Renato Pagani, Fabrizio Signorino, Pier Paolo Poli, Pietro Manzini, Irene Panisi. The use of Invisalign system in the management of the orthodontic treatment before and after Class III surgical approach. Case reports in dentistry volume 2016 (2016), Article ID 9231219, 10 pages.

17. Ravera S, Castroflorio T, Garino F, Daher S, Cugliari G, Deregibus A. Maxillary molar distalization with aligners in adult patients: a multicenter retrospective study. Prog Orthod. 2016;17(12) https://doi.org/10.1186/ s40510-016-0126-0. Epub 2016 Apr 18

18. Clinical considerations for class II treatments. [Document on the internet] Align Technology; 2013. Available from https://learn.invisalign.com/classll . Accessed 26 June 2018.

19. Clinical considerations for class III treatments. [Document on the internet] Align Technology; 2013. Available from https://learn.invisalign.com/classIII. Accessed 26 June 2018.

20. Align Techonology. Align Technology introduces Invisalign G4. San Jose: Align Techonology; 2011. Available from http://investor.aligntech.com/index. php/news-releases/news-release-details/align-technology-introducesinvisalign-g4. Cited 11 Oct 2011.

21. Align Techonology. Align Techonology announces Invisalign G5 innovations for treatment of deep bite. San Jose: Align Techonology; 2013. Available from http://investor.aligntech.com/index.php/news-releases/news-releasedetails/align-technology-announces-invisalign-g5-innovations-treatment Cited 3 Dec 2013.

22. Align Technology. Align Technology announces Invisalign G6 clinical innovations for orthodontic treatment of first premolar extractions. San Jose: Align Technology; 2014. Available from http://investor.aligntech.com/ index.php/news-releases/news-release-details/align-technology-announcesinvisalign-g6-clinical-innovations . Cited 14 Nov 2014

\section{Submit your manuscript to a SpringerOpen ${ }^{\circ}$ journal and benefit from:}

- Convenient online submission

- Rigorous peer review

- Open access: articles freely available online

- High visibility within the field

- Retaining the copyright to your article

Submit your next manuscript at $\boldsymbol{\nabla}$ springeropen.com 